OPEN ACCESS

Edited by:

Rocío Martínez De Pablos Universidad de Sevilla, Spain

Reviewed by: Miguel Angel Burguillos, University of Cambridge, United Kingdom Mikko Airavaara, University of Helsinki, Finland

*Correspondence: Bernd L. Fiebich bernd.fiebich@uniklinik-freiburg.de Antonio Carlos Pinheiro de Oliveira antoniooliveira@icb.ufmg.br

Received: 30 May 2018 Accepted: 10 September 2018 Published: 02 October 2018

Citation:

Fiebich BL, Batista CRA, Saliba SW Yousif NM and de Oliveira ACP (2018) Role of Microglia TLRs in Neurodegeneration. Front. Cell. Neurosci. 12:329. doi: 10.3389/fncel.2018.00329

\section{Role of Microglia TLRs in Neurodegeneration}

\author{
Bernd L. Fiebich ${ }^{1 *}$, Carla Ribeiro Alvares Batista ${ }^{2}$, Soraya Wilke Saliba ${ }^{1,3}$, \\ Nizar M. Yousif ${ }^{1,3}$ and Antonio Carlos Pinheiro de Oliveira ${ }^{2 *}$ \\ ${ }^{1}$ Neuroimmunology and Neurochemistry Research Group, Department of Psychiatry and Psychotherapy, Medical \\ Center-University of Freiburg, Faculty of Medicine, University of Freiburg, Freiburg, Germany, ${ }^{2}$ Department of \\ Pharmacology, Universidade Federal de Minas Gerais, Belo Horizonte, Brazil, ${ }^{3}$ Faculty of Biology, University of Freiburg, \\ Freiburg, Germany
}

Toll-like receptors (TLRs) are a group of receptors widely distributed in the organism. In the central nervous system, they are expressed in neurons, astrocytes and microglia. Although their involvement in immunity is notorious, different articles have demonstrated their roles in physiological and pathological conditions, including neurodegeneration. There is increasing evidence of an involvement of TLRs, especially TLR2, 4 and 9 in neurodegenerative diseases such as Alzheimer's disease (AD), Parkinson's disease (PD), and amyotrophic lateral sclerosis (ALS). In this sense, their expression in microglia might modulate the activity of these cells, which in turn, lead to protective or deleterious effects over neurons and other cells. Therefore, TLRs might mediate the link between inflammation and neurodegenerative diseases. However, further studies have to be performed to elucidate the role of the other TLRs in these diseases and to further prove and confirm the pathophysiological role of all TLRs in neurodegeneration. In this article, we revise and summarize the current knowledge regarding the role of TLRs in neurodegeneration with the focus on the possible functions of these receptors in microglia.

\footnotetext{
Keywords: toll-like receptors (TLRs), microglia, neurodegenerative diseases, neuroinflammation, Alzheimer's disease, Parkinson's disease, inflammatory mediators
}

\section{GENERAL ASPECTS OF TOLL-LIKE RECEPTORS}

Toll-like receptors (TLRs) are a growing family that plays critical roles in innate immune responses. Several TLRs have already been identified in human and murine, such as TLR1-5 (Chaudhary et al., 1998; Rock et al., 1998), TLR6 (Takeuchi et al., 1999), TLR7-9 (Du et al., 2000). TLRs are located on the plasma membrane with the exception of TLR3, TLR7, TLR9 that are presented intracellularly in vesicles such as the endoplasmic reticulum, endosomes or lysosomes (Kawai and Akira, 2010).

\section{SIGNALING}

TLRs are activated by different pathogen-associated molecular patterns (PAMPs), including compounds derived from bacteria, virus, or fungi (Takeuchi et al., 2002; Li et al., 2013). TLR signaling pathways depend on receptor dimerization and recruitment of adapter proteins that mediate other protein-protein interactions, such as myeloid differentiation primary-response 
protein 88 (MyD88) and Toll/interleukin 1 receptor (TIR) domain-containing adaptor interferon- $\beta$ (TRIF; Takeda et al., 2003; Yamamoto et al., 2003a). Importantly, all TLR signaling pathways are dependent on MyD88, except TLR3, which initiates signaling via the TRIF adapter. In addition, TLR4 is activated by both MyD88-associated and TRIF-related adapter molecule (TRAM)-associated pathways (Fitzgerald et al., 2003a; Ruckdeschel et al., 2004).

The MyD88-dependent pathway initiates with the recruitment of tumor-necrosis-factor-receptor-associated factor 6 (TRAF6) and members of the IL-1R-associated kinases (IRAK) family. The activation of TRAF6 allows the translocation of nuclear factor kappa B (NF-кB) to the nucleus, which results in the production of different pro-inflammatory mediators such as cytokines and cyclooxygenase-2 (COX-2; Zhang et al., 1999; Takeda and Akira, 2004; Broad et al., 2007; Kawai and Akira, 2010).

While the MyD88-dependent pathway promotes the production of pro-inflammatory cytokines, the MyD88independent pathway is associated with the induction of interferon (IFN)-inducible genes and maturation of dendritic cells (Yamamoto et al., 2003b). The MyD88-independent pathway is mediated by TRAM and TRIF. Inhibitor of NF- $\kappa$ B kinase subunit epsilon (IKKE) and TANK-binding kinase (TBK) 1 interact with TRIF or TRAM and activate interferon regulatory factor 3 (IRF-3) and NF- $\mathrm{B}$-dependent signaling pathways (Fitzgerald et al., 2003b; Palsson-McDermott and O'Neill, 2004). IRF3 mediates the expression of IFN type I, e.g., IFN- $\beta$ and chemokines, such as $\mathrm{C}-\mathrm{C}$ motif chemokine ligand 5 (CCL5) and C-X-C motif chemokine ligand 10 (CXCL10; Schafer et al., 1998; Melchjorsen and Paludan, 2003).

\section{TLR EXPRESSION IN THE CNS}

TLRs are widely expressed in the CNS and play different roles in cell survival or death (Okun et al., 2011). Studies have demonstrated that TLRs are expressed in neurons (Tang et al., 2007), microglia (Olson and Miller, 2004), astrocytes (Bowman et al., 2003), oligodendrocytes (Lehnardt et al., 2006) and neural stem cells (NSC; Okun et al., 2009; van Noort and Bsibsi, 2009). It has been demonstrated that NSC transplantation in APP/PS1 mice decreased inflammatory injury through suppression of glial and TLR4-mediated inflammatory pathway activation (Zhang et al., 2016). The expression of TLRs is affected by aging, which is a risk factor of neurodegenerative diseases, such as Alzheimer's disease (AD). Aged cultures of rat hippocampal neurons presented an increase of TLR4 expression (Calvo-Rodríguez et al., 2017) while the expression levels of TLR2 and TLR4 increased during the suckling period and then decreased once the infants reached 1 year of age (Savino et al., 2018).

Microglia are the resident mononuclear immune cells of the CNS and play important roles in the maintenance of homeostasis and neuroinflammation (Ransohoff and Perry, 2009; Perry et al., 2010; Boche et al., 2013). Microglia express all TLRs and their adapter proteins as shown in mice, rats, and humans (Bsibsi et al., 2002; Olson and Miller, 2004; Zhang et al., 2013), such as TLR1 and TLR6 (Bsibsi et al., 2002), TLR2 (Laflamme et al., 2001), TLR3, TLR5, TLR7, TLR8 (Bsibsi et al., 2002), TLR4 (Laflamme and Rivest, 2001) and TLR9 (Dalpke et al., 2002). Constitutive expression of TLRs is primarily in microglia and largely restricted to the circumventricular organs (CVOs) and meninges, areas with direct access to the circulation, although they may also be expressed at lower levels in other regions (Laflamme et al., 2001; Laflamme and Rivest, 2001; Chakravarty and Herkenham, 2005).

Different stimuli may lead to increased expression of microglia TLRs, such as hypoxia (Smith et al., 2013; Yao et al., 2013), LPS (Kielian et al., 2005; Yousif et al., 2018), Poly(I:C; Yousif et al., 2018), kainic acid (Wang et al., 2015; Hu and Mao, 2016), $\alpha$-synuclein (Béraud et al., 2011; Daniele et al., 2015) and amyloid beta (A $\beta$; Jana et al., 2008; Richard et al., 2008; Caldeira et al., 2017).

\section{TLRs IN NEURODEGENERATION}

TLR activation can be beneficial or detrimental to the host. In addition to the known role of being pro-inflammatory in the protective response against pathogens in the CNS, TLRs may be activated in the absence of microbial invaders. It has been shown that TLRs are upregulated in brains of $\mathrm{AD}$ patients (Liu et al., 2005) and other neurodegenerative diseases (Bsibsi et al., 2002; Walter et al., 2006), such as amyotrophic lateral sclerosis (ALS) and Parkinson's disease (PD; van Noort and Bsibsi, 2009; De Paola et al., 2012; Lee et al., 2015). An increased expression of TLR2, TLR4, TLR5, TLR7, TLR9 and the TLR co-receptor CD14 has been shown in microglia cells situated around senile plaques in post-mortem brain of $\mathrm{AD}$ patients and related mouse models (Liu et al., 2005; Walter et al., 2007; Jana et al., 2008; Letiembre et al., 2009). Another study demonstrated a significant alteration of cognitive functions in TLR2-deficient APP/PS1 mice and synaptic plasticity associated with increased levels of toxic A $\beta 1-42$ (Richard et al., 2008). Further studies associated TLRs with ALS in mouse models, suggesting their crucial role in the neurodegenerative process of this pathological condition (De Paola et al., 2012; Lee et al., 2015).

Finally, a crosstalk between TLR and cell stressors has been observed in immune cells, such as the unfolded protein response (UPR) and oxidative stress, which are present in different neurodegenerative diseases (Qin et al., 2005; Gill et al., 2010; Gough, 2010; Coope et al., 2012; Grootjans et al., 2016; Sprenkle et al., 2017; Wang et al., 2017). Besides, various components present in neurodegenerative diseases, which will be discussed below, activate the TLRs present in microglia. In this sense, many stimuli modulate the activity of these receptors and alter microglia phenotype and activation. Thus, TLRs present in microglia may partially mediate the development of these pathological conditions.

\section{TLR2}

TLR2 is one of the most studied TLR in respect to neurodegenerative diseases (Guillot-Sestier and Town, 2018). 
In microglia, the coupling of CD14 to TLR2 and TLR4 is necessary for the induction of immune response associated with fibrillar A $\beta$ phagocytosis (Reed-Geaghan et al., 2009). Moreover, it was reported that activation of TLR2 in microglia enhances pathological A $\beta$ uptake (Chen et al., 2006). However, others showed that inhibition of TLR2 activation decreased glial cell reactivity, leading to reduced $A \beta$ deposits and improved cognitive performance in APP/PS1 mice (McDonald et al., 2016). Likewise, knocking out TLR2 in mice prevented memory impairment occurring after A $\beta 1-42$ immunization (Vollmar et al., 2010). This is supported by results from cultured microglia showing that TLR2 deficiency reduced A $\beta 42$-induced inflammation and enhanced A $\beta$ clearance (Jana et al., 2008; Liu et al., 2012). In accordance, TLR2-dependent JNK/NF- $\kappa$ B signaling partially contributed to the inflammatory response mediated by A $\beta 1-42$ (Lin et al., 2013). Immunohistochemistry data demonstrated the TLR2 localization on microglia associated with $\mathrm{A} \beta$ plaques in old APP23 transgenic mice (Frank et al., 2009). Genetic studies identified TLR2 as one of the risk factors associated with Late-Onset $\mathrm{AD}$ (LOAD) in Azeri Turk ancestry and Han Chinese populations (Wang et al., 2011; Yu et al., 2011a; Rezazadeh et al., 2016). However, results from another report argue against the relationship between TLR2 polymorphism and LOAD (Yu et al., 2011b).

The potential role of TLR2 in PD is supported by the existing link between TLR2 polymorphism and increased risk of PD (Kalinderi et al., 2013). $\alpha$-synuclein released by neurons extracellularly acts as an endogenous ligand for TLR2 on microglia, which in turn produce toxic molecules leading to neurodegeneration (Kim et al., 2013, 2016). In mice, overexpression of $\alpha$-synuclein increased TLR2 expression and led to increased microglial activation (Drouin-Ouellet et al., 2015). Disease stage and region-dependent expression of TLR2 consistent with region-specific phenotype and activation of microglia shown in different groups of PD patients suggest a critical role of TLR2 in the microglia-related responses observed in PD (Doorn et al., 2014). Upon treatment with $\alpha$-synuclein, microglia exhibit pro-inflammatory phenotype by forming a heterodimer complex that engage TLR1 and TLR2, leading to a chronic neuroinflammatory milieu. In this context, candesartan cilexetil, a drug used for treatment of hypertension also known to suppress the expression of TLR2, reversed the pro-inflammatory microglia phenotype activated by $\alpha$-synuclein exposure (Daniele et al., 2015). Interestingly, TLR2 and its downstream signaling were shown to play a key role in the neuroprotective effects achieved through exercise approaches in 1-methyl-4-phenyl-1,2,3,6-tetrahydropyridine (MPTP) mouse model of PD (Jang et al., 2017; Koo et al., 2017).

Furthermore, induced expression of TLR2 was detected strictly within microglia in the chronically LPS-stimulated SOD1 transgenic mouse model of ALS. The increased TLR2 expression was strongly correlated with robust immune response and degeneration of motor neurons and motor axons (Nguyen et al., 2004). Another report demonstrated that overexpression of ALS-related SOD1 mutant promotes microglia neurotoxic effects via TLR2 (Liu et al., 2009). The fact that marked upregulation of TLR2 has already been observed in a previous study implemented in the ALS mouse model is in line with these findings (Nguyen et al., 2001). In two culture models of mSOD1-linked ALS, microglia TLR2 dependent activation was required to induce toxic effects and injury of motoneurons (Zhao et al., 2010). Increased expression of TLR2 in reactive glial cells was detected in spinal cord of ALS patients. Interestingly, TLR2 was mainly detected in myeloid cells (microglia, macrophages; Casula et al., 2011). Taken together, the role of microglial TLR2 in ALS seems to be consistent, since data from various reports are in agreement. This fact also suggests that modulation of TLR2 in ALS might be a potential target for effective therapy.

\section{TLR3}

TLR3 is less studied in respect to neurodegenerative diseases, although it may be involved in neuroinflammation. For example, incubation of microglia with Poly(I:C), a TLR3 agonist, increases the synthesis of COX-2, mPGES-1 and prostaglandin $\mathrm{E}_{2}$ release (de Oliveira et al., 2016), and increased the expression of TLR3 (Yousif et al., 2018). The production of these inflammatory mediators might contribute to neurodegenerative processes observed in some conditions. Indeed, a previous study shows that peripheral challenge with Poly $(\mathrm{I}: \mathrm{C})$ increased $\mathrm{A} \beta$ levels in the hippocampus linked to cognitive dysfunction in non-transgenic mice (Weintraub et al., 2014). Moreover, systemic challenge with Poly(I:C) amplified CNS inflammation and exacerbated chronic neurodegeneration in the ME7 model of prion disease (Field et al., 2010). Importantly, a very recent study in human AD brains identified increased expression of TLR3 in microglia associated with $A \beta$ plaques (Walker et al., 2018). In addition, TLR3 is an essential receptor for viral detection (Hanke and Kielian, 2011). It has already been shown that influenza virus infection may lead to neurodegeneration (Jang et al., 2009). Other viruses such as hepatitis $\mathrm{C}$ virus, Eppstein-Barr virus and human immunodeficiency virus (HIV) have been also linked to PD (Woulfe et al., 2014; Moulignier et al., 2015; Wu et al., 2015).

\section{TLR4}

An elegant and recent study demonstrated that microglia immune memory shapes neuropathology and provided potential mechanism for LPS-triggered immune memory in the brain, suggesting a role of TLR4 in this phenomenon (Wendeln et al., 2018). Interestingly, both, beneficial and detrimental roles of TLR4 in the context of AD are reported. Transgenic AD mice deficient in TLR4 exhibit reduced microglial activation, increased $\mathrm{A} \beta$ deposition, and reduced cognitive function (Song et al., 2011). In the transgenic mouse model of tau pathology P301S, chronic mild stimulation of TLR4 with LPS reduced cerebral p-tau proteins and improved memory impairment through microglia-dependent activation of autophagy (Qin et al., 2016). In contrast, activation of TLR4 but not TLR2 reduced microglial 
A $\beta 42$-clearance through modulation of the scavenger receptor CD36 activity (Li et al., 2015). Pronounced TLR4 expression in APP mice and an increased expression of TLR4 in brains of $\mathrm{AD}$ patients associated with $\mathrm{A} \beta$ plaques have been identified (Walter et al., 2007). TLR4 was shown to be necessary for glial cell activation that resulted in impairment in memory in a mouse model of $\mathrm{AD}$ based on acute $A \beta$ injection (Balducci et al., 2017). A recent report suggests that alteration in microglial TLR4 signaling contribute to $\mathrm{AD}$ pathogenesis in $\mathrm{APP} / \mathrm{PS} 1$ mice (Go et al., 2016).

Collectively, the role of TLR4, likewise TLR2, in AD is perhaps disease-stage dependent and this could be at least one explanation for the controversy found in the literature about the impact of these receptors in $\mathrm{AD}$ pathology. In this regard, activation of TLR4 in the initial stage has beneficial effects on $A \beta$-clearance, while chronic activation contributes to $A \beta$ aggregation (Huang et al., 2017).

Previous studies suggest that TLR4 deregulation may play an important role in $\alpha$-synucleinopathies (Caputi and Giron, 2018). TLR4 was shown to be essential for microglia to induce responses against $\alpha$-synuclein in vitro such as uptake of this protein, pro-inflammatory cytokine release, and reactive oxygen species production (ROS; Fellner et al., 2013). TLR4 deficiency in the MPTP induced PD model resulted in reduced cell death and decreased number of reactive microglia (Noelker et al., 2013). Impaired microglial phagocytosis, enhanced neuronal loss and exacerbated motor dysfunction upon TLR4 ablation has been shown in a transgenic mouse model of multiple system atrophy with oligodendroglial $\alpha$-synuclein overexpression (Stefanova et al., 2011). Moreover, stimulation of TLR4 with monophosphoryl lipid A in mice overexpressing $\alpha$-synuclein increased microglia phagocytosis of this protein, improved motor deficits, and prevented neuronal degeneration (Venezia et al., 2017). In BV2 microglia-like cells, TLR4-dependent immune response regulated Nurr1 and NF- $\mathrm{B}$ signals, which were shown to be vital during neuroinflammation stimulated by $\alpha$-synuclein (Shao et al., 2018). In addition, TLR4 signaling was shown to exert a crucial function in the activation of BV2 cells and the promotion of inflammation induced by 1-methyl-4-phenylpyridinium (MPP(+); Zhou et al., 2016). In an in vitro model of $\mathrm{PD}$, neuron-derived IgG mediates dopaminergic neurons survival by reducing apoptosis induced by 6-hydroxydopamine toxicity through a mechanism that involved the activation of microglial TLR4 (Zhang et al., 2013). Taken together, TLR4 seems to exert different roles in relation to PD. Nevertheless, future investigations aiming to target TLR4 in a specific cell subset in the brain will provide a better understanding concerning the role of this receptor in the context of PD.

Recently, the impact of TLRs in respect to ALS has been given some attention. For instance, in the hSOD1 G93A mouse model of ALS, increased TLR4 expression has been detected in microglia and astrocytes. In the same model, TLR4 deficiency improved motor function and extended life expectancy (Lee et al., 2015). In vitro and in vivo approaches of motor neuron degeneration, treatment with TLR4 antagonist decreased microglial activation, exerted neuroprotective effects, and improved behavior performance (De Paola et al., 2012). In line with these findings, antagonizing TLR4 in motoneurons/glia co-cultures isolated from SOD1 G93A mice prevented cell death induced by SOD1mut glia (De Paola et al., 2016).

The role of TLRs in Huntington's disease (HD) is not covered. There is only one study that directly addressed the importance of TLR2, TLR3 and TLR4 in the N171-82Q mouse model of HD. In this study, when TLR2, TLR3 and TLR4 were lacking, the survival rate of HD mice was increased (Griffioen et al., 2018).

\section{TLR5}

In the context of neurodegenerative diseases, Bsibsi et al. (2002) have demonstrated that human microglial cell cultures from donors with $\mathrm{AD}$, olivopontocerebellar atrophy (OPCA), and Pick's disease (PID) expressed increasing levels of TLR5 but differing between the donors. Additionally, overexpression of TLR5 in the substantia nigra, striatum, cerebral cortex and nucleus dentatus areas, was observed in multiple systems atrophy patients (Brudek et al., 2013) and in the brain stem of a genetic PD mouse model (Letiembre et al., 2009). In contrast, down-regulation of TLR5 expression was observed in the frontal cortex of a PD rat model, using intranasal administration of MPTP (Viana et al., 2017). However, additional studies are needed to elucidate the effects of TLR5 in neurodegenerative diseases and to comprehend its role in microglia.

\section{TLR7}

The expression of TLR7 has been demonstrated in different neurodegenerative diseases (AD, PD, OPCA and PID) and in disease models including human microglial cell culture (Bsibsi et al., 2002) or murine microglial cells (Béraud et al., 2011; Béraud and Maguire-Zeiss, 2012). Furthermore, the expression of TLR7 has also been demonstrated in some areas of the CNS of genetic mice models of AD (brain cortex) and ALS (spinal cord; Letiembre et al., 2009; Liu et al., 2017). Other studies have demonstrated that TLR7 activation induced neurodegeneration. Rosenberger et al. (2014) have shown that activation of TLR7 in neurons, but not in microglia, significantly enhanced apoptosis in co-cultures and the TLR7 agonist (loxoribine) induced loss of neurons, axonal injury in the cerebral cortex and pronounced microglia activation in the mouse brain. Another study has verified the activation of TLR7 by microRNA let-7, a regulator of gene expression in the CNS, which induced neurodegeneration independent of microglia (Lehmann et al., 2012a). In contrast, the same group has shown TLR7 activation by ssRNA40induced neuronal cell death through microglia (Lehmann et al., 2012b).

In a transgenic mouse model of $\mathrm{AD}$, deletion of TLR7 ameliorates spatial learning, but did not affect microglia activation, cytokine expression, or $\mathrm{A} \beta$ deposition (Liu et al., 2017). 
Nevertheless, the activation of TLR7 has been described to induce autophagy (Delgado et al., 2008) and has been proposed to be involved in the $A \beta$ clearance by microglia (Gambuzza et al., 2014). Further studies have to be performed to elucidate the function of TLR7 in autophagy and its impact in neurodegenerative diseases.

At present, the role of microglial TLR7 in neurodegenerative diseases remains elusive. However, one potential strategy to

TABLE 1 | Expression and potential roles of TLR in neurodegenerative conditions.

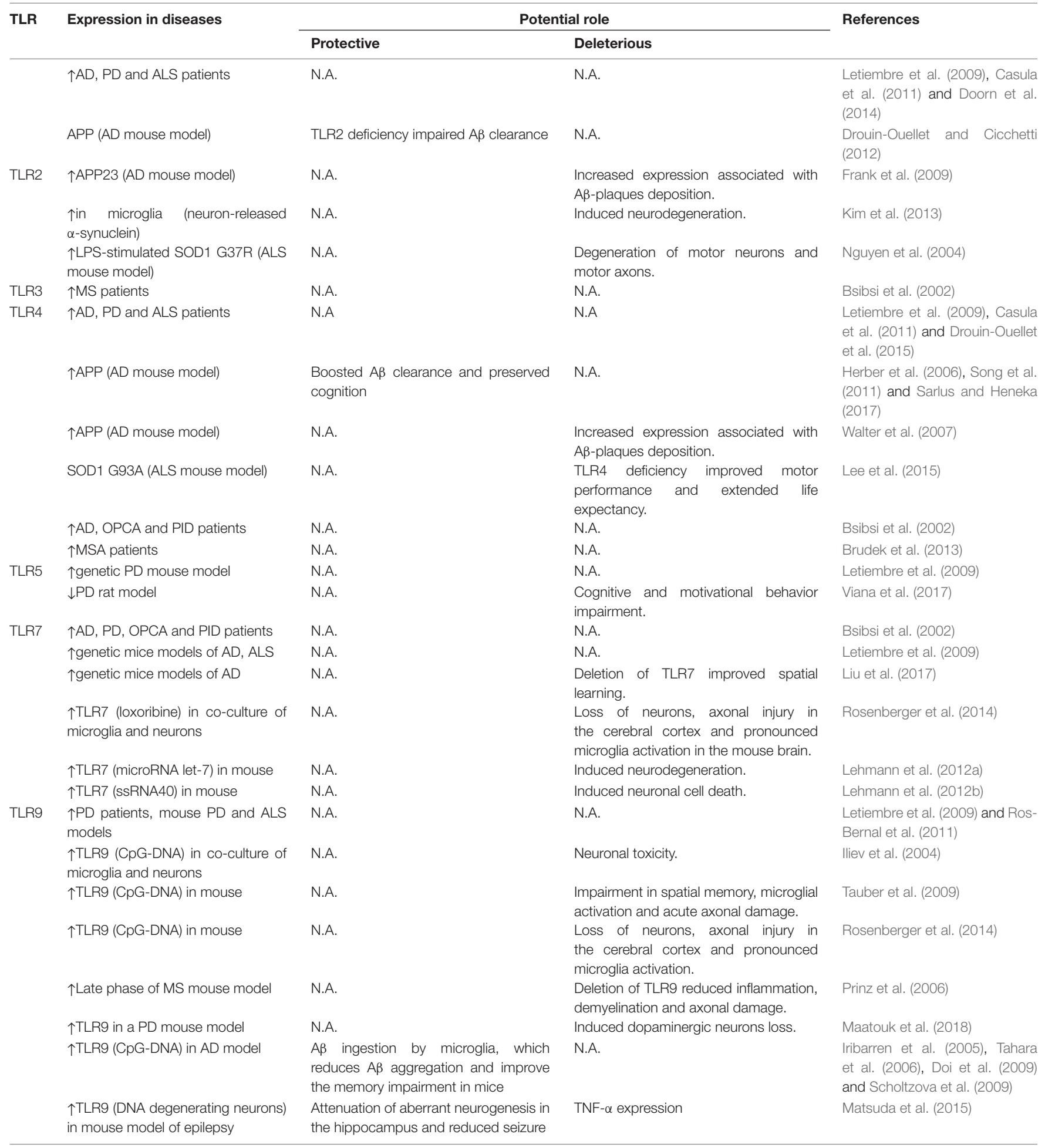

个increase; $\downarrow$ decrease; N.A. - not available. 
address this issue would be to use a TLR7 knockdown model specifically in microglia and associate it with models of neurodegeneration.

\section{TLR9}

TLR9 is overexpressed in brain regions such as substantia nigra and putamen from PD patients (Ros-Bernal et al., 2011), in striatum of a PD mouse model (Ros-Bernal et al., 2011), and in the spinal cord in an ALS mouse model (Letiembre et al., 2009).

Some studies have demonstrated that the activation of TLR9 signaling exacerbate neurodegeneration by inducing oxidative stress and inflammation. CpG-DNA activated microglia and induced TNF- $\alpha$ and nitric oxide (Dalpke et al., 2002; Ebert et al., 2005). In a co-culture containing microglia and neurons, the activation of microglial cells by CpG-DNA via TLR9 induced neuronal toxicity mediated partially through TNF- $\alpha$ (Iliev et al., 2004). Intracerebroventricular infusions of CpG-DNA caused impairment in spatial memory, microglia activation and acute axonal damage (Tauber et al., 2009). Furthermore, intrathecal injection of CpG oligodeoxynucleotide (ODN) induced loss of neurons, axonal injury in the cerebral cortex, and pronounced microglia activation (Rosenberger et al., 2014). TLR9-deficient mice demonstrated reduction of inflammation, demyelination and axonal damage during the late phase of an MS mouse model (Prinz et al., 2006). It was also hypothesized that a reduced glucocorticoid receptor activity in $\mathrm{PD}$ due to chronically high cortisol levels could lead to TLR9 activation by components released by dopaminergic neurons, which could, in turn, exacerbate the death of these cells (Maatouk et al., 2018).

On the other hand, a neuroprotective role of microglia through activation of TLR9 has been suggested. In an AD mouse model, activation of TLR9 by CpG ODN appears to be involved in the enhanced $A \beta$ ingestion by microglia, which reduces $A \beta$ aggregation and improves memory impairment (Iribarren et al., 2005; Tahara et al., 2006; Doi et al., 2009; Scholtzova et al., 2009). In a mouse model of epilepsy, activation of TLR9 in microglia by DNA from degenerating neurons induced TNF- $\alpha$ expression. Moreover, this TLR9 activation in microglia resulted in the attenuation of aberrant neurogenesis in

\section{REFERENCES}

Balducci, C., Frasca, A., Zotti, M., La Vitola, P., Mhillaj, E., Grigoli, E., et al. (2017). Toll-like receptor 4-dependent glial cell activation mediates the impairment in memory establishment induced by $\beta$-amyloid oligomers in an acute mouse model of Alzheimer's disease. Brain Behav. Immun. 60, 188-197. doi: 10.1016/j. bbi.2016.10.012

Béraud, D., and Maguire-Zeiss, K. A. (2012). Misfolded $\alpha$-synuclein and toll-like receptors: therapeutic targets for Parkinson's disease. Parkinsonism Relat. Disord. 18, S17-S20. doi: 10.1016/S1353-8020(11) 70008-6

Béraud, D., Twomey, M., Bloom, B., Mittereder, A., Ton, V., Neitzke, K., et al. (2011). $\alpha$-synuclein alters toll-like receptor expression. Front. Neurosci. 5:80. doi: $10.3389 /$ fnins. 2011.00080 the hippocampus and reduced seizure mediated by kainic acid (Matsuda et al., 2015). These studies suggest that microglial TLR9 could be involved in neuroprotection in various neurodegenerative diseases.

\section{CONCLUSION AND FUTURE PERSPECTIVES}

TLRs are involved in a plethora of physiological and pathological mechanisms. Activation of both endosomal and plasma membrane receptors control the microglial activity and may alter its phenotypes, which could control the evolution of neurodegenerative processes (Table 1). Thus, TLRs could represent potential pharmacological targets for the development of neuroprotective drugs. However, the current knowledge on the effects and pathways modulated by them in microglia is still modest and further studies are necessary to establish their exact roles neuropathological events. Finally, studies that specifically delete these receptors in microglia using models of neurodegeneration could contribute to clarify their roles in these pathological conditions.

\section{AUTHOR CONTRIBUTIONS}

AO reviewed the literature, designed, wrote part of and revised the manuscript. $\mathrm{CB}$, SS and NY reviewed the literature, wrote part of the manuscript. BF reviewed the literature, designed the manuscript and revised it.

\section{FUNDING}

We thank Fundação de Amparo à Pesquisa do Estado de Minas Gerais (FAPEMIG; \#CBB-APQ-02044-15) and Conselho Nacional de Desenvolvimento Científico e Tecnológico (CNPq; \#424588-2016-1) for the financial support. SS acknowledges $\mathrm{CNPq} / \mathrm{CSF}$ (Brasília/Brazil) and DAAD (Germany) for the fellowship. AO acknowledges $\mathrm{CNPq}$ for the Research Productivity Fellowship (\#309718/2015-5). NY was supported by a scholarship as per the State Law on Graduate Funding (LGFGIGA, Freiburg). The article processing charge was funded by the University of Freiburg in the funding program Open Access Publishing.

Boche, D., Perry, V. H., and Nicoll, J. A. R. (2013). Review: activation patterns of microglia and their identification in the human brain. Neuropathol. Appl. Neurobiol. 39, 3-18. doi: 10.1111/nan.12011

Bowman, C. C., Rasley, A., Tranguch, S. L., and Marriott, I. (2003). Cultured astrocytes express toll-like receptors for bacterial products. Glia 43, 281-291. doi: 10.1002/glia.10256

Broad, A., Kirby, J. A., Jones, D. E. J., and Applied Immunology and Transplantation Research Group. (2007). Toll-like receptor interactions: tolerance of MyD88-dependent cytokines but enhancement of MyD88-independent interferon- $\beta$ production. Immunology 120, 103-111. doi: 10.1111/j.1365-2567.2006.02485.x

Brudek, T., Winge, K., Agander, T. K., and Pakkenberg, B. (2013). Screening of toll-like receptors expression in multiple system atrophy brains. Neurochem. Res. 38, 1252-1259. doi: 10.1007/s11064-013-1020-5 
Bsibsi, M., Ravid, R., Gveric, D., and van Noort, J. M. (2002). Broad expression of toll-like receptors in the human central nervous system. J. Neuropathol. Exp. Neurol. 61, 1013-1021. doi: 10.1093/jnen/61.11.1013

Caldeira, C., Cunha, C., Vaz, A. R., Falcão, A. S., Barateiro, A., Seixas, E., et al. (2017). Key aging-associated alterations in primary microglia response to $\beta$-amyloid stimulation. Front. Aging Neurosci. 9:277. doi: 10.3389/fnagi.2017. 00277

Calvo-Rodríguez, M., de la Fuente, C., García-Durillo, M., García-Rodríguez, C., Villalobos, C., and Núñez, L. (2017). Aging and amyloid $\beta$ oligomers enhance TLR4 expression, LPS-induced $\mathrm{Ca}^{2+}$ responses, and neuron cell death in cultured rat hippocampal neurons. J. Neuroinflammation 14:24. doi: 10.1186/s12974-017-0802-0

Caputi, V., and Giron, M. C. (2018). Microbiome-gut-brain axis and toll-like receptors in Parkinson's disease. Int. J. Mol. Sci. 19:E1689. doi: 10.3390/ijms19061689

Casula, M., Iyer, A. M., Spliet, W. G. M., Anink, J. J., Steentjes, K., Sta, M., et al. (2011). Toll-like receptor signaling in amyotrophic lateral sclerosis spinal cord tissue. Neuroscience 179, 233-243. doi: 10.1016/j.neuroscience.2011. 02.001

Chakravarty, S., and Herkenham, M. (2005). Toll-like receptor 4 on nonhematopoietic cells sustains CNS inflammation during endotoxemia, independent of systemic cytokines. J. Neurosci. 25, 1788-1796. doi: 10.1523/JNEUROSCI.4268-04.2005

Chaudhary, P. M., Ferguson, C., Nguyen, V., Nguyen, O., Massa, H. F., Eby, M., et al. (1998). Cloning and characterization of two Toll/Interleukin-1 receptor-like genes TIL3 and TIL4: evidence for a multi-gene receptor family in humans. Blood 91, 4020-4027.

Chen, K., Iribarren, P., Hu, J., Chen, J., Gong, W., Cho, E. H., et al. (2006). Activation of toll-like receptor 2 on microglia promotes cell uptake of Alzheimer disease-associated amyloid $\beta$ peptide. J. Biol. Chem. 281, 3651-3659. doi: 10.1074/jbc.M508125200

Coope, A., Milanski, M., Arruda, A. P., Ignacio-Souza, L. M., Saad, M. J., Anhê, G. F., et al. (2012). Chaperone insufficiency links TLR4 protein signaling to endoplasmic reticulum stress. J. Biol. Chem. 287, 15580-15589. doi: 10.1074/jbc.M111.315218

Dalpke, A. H., Schafer, M. K.-H., Frey, M., Zimmermann, S., Tebbe, J., Weihe, E., et al. (2002). Immunostimulatory CpG-DNA activates murine microglia. J. Immunol. 168, 4854-4863. doi: 10.4049/jimmunol.168. 10.4854

Daniele, S. G., Béraud, D., Davenport, C., Cheng, K., Yin, H., and MaguireZeiss, K. A. (2015). Activation of MyD88-dependent TLR1/2 signaling by misfolded $\alpha$-synuclein, a protein linked to neurodegenerative disorders. Sci. Signal. 8:ra45. doi: 10.1126/scisignal.2005965

de Oliveira, A. C. P., Yousif, N. M., Bhatia, H. S., Hermanek, J., Huell, M., and Fiebich, B. L. (2016). Poly(I:C) increases the expression of mPGES-1 and COX-2 in rat primary microglia. J. Neuroinflammation 13:11. doi: 10.1186/s12974-015-0473-7

De Paola, M., Mariani, A., Bigini, P., Peviani, M., Ferrara, G., Molteni, M., et al. (2012). Neuroprotective effects of toll-like receptor 4 antagonism in spinal cord cultures and in a mouse model of motor neuron degeneration. Mol. Med. 18, 971-981. doi: 10.2119/molmed.2012.00020

De Paola, M., Sestito, S. E., Mariani, A., Memo, C., Fanelli, R., Freschi, M., et al. (2016). Synthetic and natural small molecule TLR4 antagonists inhibit motoneuron death in cultures from ALS mouse model. Pharmacol. Res. 103, 180-187. doi: 10.1016/j.phrs.2015.11.020

Delgado, M. A., Elmaoued, R. A., Davis, A. S., Kyei, G., and Deretic, V. (2008). Toll-like receptors control autophagy. EMBO J. 27, 1110-1121. doi: 10.1038/emboj.2008.31

Doi, Y., Mizuno, T., Maki, Y., Jin, S., Mizoguchi, H., Ikeyama, M., et al. (2009). Microglia activated with the toll-like receptor 9 ligand CpG attenuate oligomeric amyloid $\beta$ neurotoxicity in in vitro and in vivo models of Alzheimer's disease. Am. J. Pathol. 175, 2121-2132. doi: 10.2353/ajpath.2009. 090418

Doorn, K. J., Moors, T., Drukarch, B., van de Berg, W. D., Lucassen, P. J., and van Dam, A.-M. (2014). Microglial phenotypes and toll-like receptor 2 in the substantia nigra and hippocampus of incidental Lewy body disease cases and Parkinson's disease patients. Acta Neuropathol. Commun. 2:90. doi: $10.1186 / s 40478-014-0090-1$
Drouin-Ouellet, J., and Cicchetti, F. (2012). Inflammation and neurodegeneration: the story 'retolled'. Trends Pharmacol. Sci. 33, 542-551. doi: 10.1016/j.tips.2012. 07.002

Drouin-Ouellet, J., St-Amour, I., Saint-Pierre, M., Lamontagne-Proulx, J., Kriz, J., Barker, R. A., et al. (2015). Toll-like receptor expression in the blood and brain of patients and a mouse model of Parkinson's disease. Int. J. Neuropsychopharmacol. 18:pyu103. doi: 10.1093/ijnp/pyu103

Du, X., Poltorak, A., Wei, Y., and Beutler, B. (2000). Three novel mammalian toll-like receptors: gene structure, expression, and evolution. Eur. Cytokine Netw. 11, 362-371.

Ebert, S., Gerber, J., Bader, S., Mühlhauser, F., Brechtel, K., Mitchell, T. J., et al. (2005). Dose-dependent activation of microglial cells by Toll-like receptor agonists alone and in combination. J. Neuroimmunol. 159, 87-96. doi: 10.1016/j.jneuroim.2004.10.005

Fellner, L., Irschick, R., Schanda, K., Reindl, M., Klimaschewski, L., Poewe, W., et al. (2013). Toll-like receptor 4 is required for $\alpha$-synuclein dependent activation of microglia and astroglia. Glia 61, 349-360. doi: 10.1002/glia. 22437

Field, R., Campion, S., Warren, C., Murray, C., and Cunningham, C. (2010). Systemic challenge with the TLR3 agonist poly I:C induces amplified IFN $\alpha / \beta$ and IL- $1 \beta$ responses in the diseased brain and exacerbates chronic neurodegeneration. Brain Behav. Immun. 24, 996-1007. doi: 10.1016/j.bbi. 2010.04.004

Fitzgerald, K. A., McWhirter, S. M., Faia, K. L., Rowe, D. C., Latz, E., Golenbock, D. T., et al. (2003a). IKKE and TBK1 are essential components of the IRF3 signaling pathway. Nat. Immunol. 4, 491-496. doi: 10.1038/ ni921

Fitzgerald, K. A., Rowe, D. C., Barnes, B. J., Caffrey, D. R., Visintin, A., Latz, E., et al. (2003b). LPS-TLR4 signaling to IRF-3/7 and NF-KB involves the toll adapters TRAM and TRIF. J. Exp. Med. 198, 1043-1055. doi: 10.1084/jem. 20031023

Frank, S., Copanaki, E., Burbach, G. J., Müller, U. C., and Deller, T. (2009). Differential regulation of toll-like receptor mRNAs in amyloid plaqueassociated brain tissue of aged APP23 transgenic mice. Neurosci. Lett. 453, 41-44. doi: 10.1016/j.neulet.2009.01.075

Gambuzza, M., Sofo, V., Salmeri, F., Soraci, L., Marino, S., and Bramanti, P. (2014). Toll-like receptors in Alzheimer's disease: a therapeutic perspective. CNS Neurol. Disord. Drug Targets 13, 1542-1558. doi: $10.2174 / 1871527313666140806124850$

Gill, R., Tsung, A., and Billiar, T. R. (2010). Linking oxidative stress to inflammation: toll-like receptors. Free Radic. Biol. Med 48, 1121-1132. doi: 10.1016/j.freeradbiomed.2010.01.006

Go, M., Kou, J., Lim, J.-E., Yang, J., and Fukuchi, K. (2016). Microglial response to LPS increases in wild-type mice during aging but diminishes in an Alzheimer's mouse model: Implication of TLR4 signaling in disease progression. Biochem. Biophys. Res. Commun. 479, 331-337. doi: 10.1016/j.bbrc.2016.09.073

Gough, N. R. (2010). UPR to TLR connection. Sci. Signal. 3:ec124. doi: 10.1126/scisignal.3119ec124

Griffioen, K., Mattson, M. P., and Okun, E. (2018). Deficiency of Toll-like receptors 2, 3 or 4 extends life expectancy in Huntington's disease mice. Heliyon 4:e00508. doi: 10.1016/j.heliyon.2018.e00508

Grootjans, J., Kaser, A., Kaufman, R. J., and Blumberg, R. S. (2016). The unfolded protein response in immunity and inflammation. Nat. Rev. Immunol. 16, 469-484. doi: 10.1038/nri.2016.62

Guillot-Sestier, M. V., and Town, T. (2018). Let's make microglia great again in neurodegenerative disorders. J. Neural Transm. 125, 751-770. doi: $10.1007 / \mathrm{s} 00702-017-1792-\mathrm{x}$

Hanke, M. L., and Kielian, T. (2011). Toll-like receptors in health and disease in the brain: mechanisms and therapeutic potential. Clin. Sci. 121, 367-387. doi: $10.1042 / \mathrm{cs} 20110164$

Herber, D. L., Maloney, J. L., Roth, L. M., Freeman, M. J., Morgan, D., and Gordon, M. N. (2006). Diverse microglial responses after intrahippocampal administration of lipopolysaccharide. Glia 53, 382-391. doi: 10.1002/glia. 20272

Hu, Q.-P., and Mao, D.-A. (2016). Histone deacetylase inhibitor SAHA attenuates post-seizure hippocampal microglia TLR4/MYD88 signaling and inhibits TLR4 gene expression via histone acetylation. BMC Neurosci. 17:22. doi: 10.1186/s12868-016-0264-9 
Huang, N.-Q., Jin, H., Zhou, S., Shi, J., and Jin, F. (2017). TLR4 is a link between diabetes and Alzheimer's disease. Behav. Brain Res. 316, 234-244. doi: 10.1016/j.bbr.2016.08.047

Iliev, A. I., Stringaris, A. K., Nau, R., and Neumann, H. (2004). Neuronal injury mediated via stimulation of microglial toll-like receptor-9 (TLR9). FASEB J. 18, 412-414. doi: 10.1096/fj.03-0670fje

Iribarren, P., Chen, K., Hu, J., Gong, W., Cho, E. H., Lockett, S., et al. (2005). CpGcontaining oligodeoxynucleotide promotes microglial cell uptake of amyloid $\beta$ 1-42 peptide by up-regulating the expression of the G-protein- coupled receptor mFPR2. FASEB J. 19, 2032-2034. doi: 10.1096/fj.05-4578fje

Jana, M., Palencia, C. A., and Pahan, K. (2008). Fibrillar amyloid- $\beta$ peptides activate microglia via TLR2: implications for Alzheimer's disease. J. Immunol. 181, 7254-7262. doi: 10.4049/jimmunol.181.10.7254

Jang, H., Boltz, D., Sturm-Ramirez, K., Shepherd, K. R., Jiao, Y., Webster, R., et al. (2009). Highly pathogenic H5N1 influenza virus can enter the central nervous system and induce neuroinflammation and neurodegeneration. Proc. Natl. Acad. Sci. U S A 106, 14063-14068. doi: 10.1073/pnas.09000 96106

Jang, Y., Koo, J.-H., Kwon, I., Kang, E.-B., Um, H.-S., Soya, H., et al. (2017). Neuroprotective effects of endurance exercise against neuroinflammation in MPTP-induced Parkinson's disease mice. Brain Res. 1655, 186-193. doi: 10.1016/j.brainres.2016.10.029

Kalinderi, K., Bostantjopoulou, S., Katsarou, Z., and Fidani, L. (2013). TLR9 $-1237 T / C$ and TLR2 -194 to -174 del polymorphisms and the risk of Parkinson's disease in the Greek population: a pilot study. Neurol. Sci. 34, 679-682. doi: 10.1007/s10072-012-1106-x

Kawai, T., and Akira, S. (2010). The role of pattern-recognition receptors in innate immunity: update on Toll-like receptors. Nat. Immunol. 11, 373-384. doi: $10.1038 /$ ni.1863

Kielian, T., Esen, N., and Bearden, E. D. (2005). Toll-like receptor 2 (TLR2) is pivotal for recognition of S. aureus peptidoglycan but not intact bacteria by microglia. Glia 49, 567-576. doi: 10.1002/glia.20144

Kim, C., Ho, D.-H., Suk, J.-E., You, S., Michael, S., Kang, J., et al. (2013). Neuronreleased oligomeric $\alpha$-synuclein is an endogenous agonist of TLR2 for paracrine activation of microglia. Nat. Commun. 4:1562. doi: 10.1038/ncomms2534

Kim, C., Lee, H.-J., Masliah, E., and Lee, S.-J. (2016). Non-cell-autonomous neurotoxicity of $\alpha$-synuclein through microglial toll-like receptor 2. Exp. Neurobiol. 25, 113-119. doi: 10.5607/en.2016.25.3.113

Koo, J.-H., Jang, Y.-C., Hwang, D.-J., Um, H.-S., Lee, N.-H., Jung, J.-H., et al. (2017). Treadmill exercise produces neuroprotective effects in a murine model of Parkinson's disease by regulating the TLR2/MyD88/NF- $\mathrm{KB}$ signaling pathway. Neuroscience 356, 102-113. doi: 10.1016/j.neuroscience.2017. 05.016

Laflamme, N., Soucy, G., and Rivest, S. (2001). Circulating cell wall components derived from gram-negative, not gram-positive, bacteria cause a profound induction of the gene-encoding Toll-like receptor 2 in the CNS: cell wall components and TLR2 in the CNS. J. Neurochem. 79, 648-657. doi: 10.1046/j. 1471-4159.2001.00603.x

Laflamme, N., and Rivest, S. (2001). Toll-like receptor 4: the missing link of the cerebral innate immune response triggered by circulating gram-negative bacterial cell wall components. FASEB J. 15, 155-163. doi: 10.1096/fj.000339com

Lee, J. Y., Lee, J. D., Phipps, S., Noakes, P. G., and Woodruff, T. M. (2015). Absence of toll-like receptor 4 (TLR4) extends survival in the hSOD1G93A mouse model of amyotrophic lateral sclerosis. J. Neuroinflammation 12:90. doi: 10.1186/s12974-015-0310-z

Lehmann, S. M., Krüger, C., Park, B., Derkow, K., Rosenberger, K., Baumgart, J., et al. (2012a). An unconventional role for miRNA: let-7 activates Toll-like receptor 7 and causes neurodegeneration. Nat. Neurosci. 15, 827-835. doi: $10.1038 / \mathrm{nn} .3113$

Lehmann, S. M., Rosenberger, K., Krüger, C., Habbel, P., Derkow, K., Kaul, D., et al. (2012b). Extracellularly delivered single-stranded viral RNA causes neurodegeneration dependent on TLR7. J. Immunol. 189, 1448-1458. doi: 10.4049/jimmunol.1201078

Lehnardt, S., Henneke, P., Lien, E., Kasper, D. L., Volpe, J. J., Bechmann, I., et al. (2006). A mechanism for neurodegeneration induced by group B streptococci through activation of the TLR2/MyD88 pathway in microglia. J. Immunol. 177, 583-592. doi: 10.4049/jimmunol.177.1.583
Letiembre, M., Liu, Y., Walter, S., Hao, W., Pfander, T., Wrede, A., et al. (2009). Screening of innate immune receptors in neurodegenerative diseases: a similar pattern. Neurobiol. Aging 30, 759-768. doi: 10.1016/j.neurobiolaging. 2007.08.018

Li, X., Melief, E., Postupna, N., Montine, K. S., Keene, C. D., and Montine, T. J. (2015). Prostaglandin $E_{2}$ receptor subtype 2 regulation of scavenger receptor CD36 modulates microglial A $\beta_{42}$ phagocytosis. Am. J. Pathol. 185, 230-239. doi: 10.1016/j.ajpath.2014.09.016

Li, J., Wang, X., Zhang, F., and Yin, H. (2013). Toll-like receptors as therapeutic targets for autoimmune connective tissue diseases. Pharmacol. Ther. 138, 441-451. doi: 10.1016/j.pharmthera.2013.03.003

Lin, W., Ding, M., Xue, J., and Leng, W. (2013). The role of TLR2/JNK/NF-кB pathway in amyloid $\beta$ peptide-induced inflammatory response in mouse NG108-15 neural cells. Int. Immunopharmacol. 17, 880-884. doi: 10.1016/j. intimp.2013.09.016

Liu, S., Liu, Y., Hao, W., Wolf, L., Kiliaan, A. J., Penke, B., et al. (2012). TLR2 is a primary receptor for Alzheimer's amyloid peptide to trigger neuroinflammatory activation. J. Immunol. 188, 1098-1107. doi: 10.4049/jimmunol.1101121

Liu, Y., Hao, W., Dawson, A., Liu, S., and Fassbender, K. (2009). Expression of amyotrophic lateral sclerosis-linked SOD1 mutant increases the neurotoxic potential of microglia via TLR2. J. Biol. Chem. 284, 3691-3699. doi: 10.1074/jbc. m804446200

Liu, H.-Y., Hung, Y.-F., Lin, H.-R., Yen, T.-L., and Hsueh, Y.-P. (2017). Tlr7 deletion selectively ameliorates spatial learning but does not influence $\beta$ deposition and inflammatory response in an Alzheimers disease mouse model. Neuropsychiatry 7, 509-521. doi: 10.4172/neuropsychiatry.1000243

Liu, Y., Walter, S., Stagi, M., Cherny, D., Letiembre, M., Schulz-Schaeffer, W., et al. (2005). LPS receptor (CD14): a receptor for phagocytosis of Alzheimer's amyloid peptide. Brain 128, 1778-1789. doi: 10.1093/brain/awh531

Maatouk, L., Compagnion, A.-C., Sauvage, M.-A. C., Bemelmans, A.-P., Leclere-Turbant, S., Cirotteau, V., et al. (2018). TLR9 activation via microglial glucocorticoid receptors contributes to degeneration of midbrain dopamine neurons. Nat. Commun. 9:3109. doi: 10.1038/s41467-01805680-w

Matsuda, T., Murao, N., Katano, Y., Juliandi, B., Kohyama, J., Akira, S., et al. (2015). TLR9 signalling in microglia attenuates seizure-induced aberrant neurogenesis in the adult hippocampus. Nat. Commun. 6:6514 doi: 10.1038/ncomms7514

McDonald, C. L., Hennessy, E., Rubio-Araiz, A., Keogh, B., McCormack, W., McGuirk, P., et al. (2016). Inhibiting TLR2 activation attenuates amyloid accumulation and glial activation in a mouse model of Alzheimer's disease. Brain Behav. Immun. 58, 191-200. doi: 10.1016/j.bbi.2016. 07.143

Melchjorsen, J., and Paludan, S. R. (2003). Induction of RANTES/CCL5 by herpes simplex virus is regulated by nuclear factor $\kappa \mathrm{B}$ and interferon regulatory factor 3. J. Gen. Virol. 84, 2491-2495. doi: 10.1099/vir.0. 19159-0

Moulignier, A., Gueguen, A., Lescure, F.-X., Ziegler, M., Girard, P.-M., Cardon, B., et al. (2015). Does HIV infection alter parkinson disease? J. Acquir. Immune Defic. Syndr. 70, 129-136. doi: 10.1097/qai.0000000000000677

Nguyen, M. D., D'Aigle, T., Gowing, G., Julien, J. P., and Rivest, S. (2004). Exacerbation of motor neuron disease by chronic stimulation of innate immunity in a mouse model of amyotrophic lateral sclerosis. J. Neurosci. 24, 1340-1349. doi: 10.1523/JNEUROSCI.4786-03.2004

Nguyen, M. D., Julien, J. P., and Rivest, S. (2001). Induction of proinflammatory molecules in mice with amyotrophic lateral sclerosis: no requirement for proapoptotic interleukin-1 $\beta$ in neurodegeneration. Ann. Neurol. 50, 630-639. doi: 10.1002/ana.1256

Noelker, C., Morel, L., Lescot, T., Osterloh, A., Alvarez-Fischer, D., Breloer, M., et al. (2013). Toll like receptor 4 mediates cell death in a mouse MPTP model of Parkinson disease. Sci. Rep. 3:1393. doi: 10.1038/srep01393

Okun, E., Griffioen, K. J., and Mattson, M. P. (2011). Toll-like receptor signaling in neural plasticity and disease. Trends Neurosci. 34, 269-281. doi: 10.1016/j. tins.2011.02.005

Okun, E., Griffioen, K. J., Lathia, J. D., Tang, S.-C., Mattson, M. P., and Arumugam, T. V. (2009). Toll-like receptors in neurodegeneration. Brain Res. Rev. 59, 278-292. doi: 10.1016/j.brainresrev.2008.09.001 
Olson, J. K., and Miller, S. D. (2004). Microglia initiate central nervous system innate and adaptive immune responses through multiple TLRs. J. Immunol. 173, 3916-3924. doi: 10.4049/jimmunol.173.6.3916

Palsson-McDermott, E. M., and O'Neill, L. A. J. (2004). Signal transduction by the lipopolysaccharide receptor, Toll-like receptor-4. Immunology 113, 153-162. doi: 10.1111/j.1365-2567.2004.01976.x

Perry, V. H., Nicoll, J. A. R., and Holmes, C. (2010). Microglia in neurodegenerative disease. Nat. Rev. Neurol. 6, 193-201. doi: 10.1038/nrneurol. 2010.17

Prinz, M., Garbe, F., Schmidt, H., Mildner, A., Gutcher, I., Wolter, K., et al. (2006). Innate immunity mediated by TLR 9 modulates pathogenicity in an animal model of multiple sclerosis. J. Clin. Invest. 116, 456-464. doi: 10.1172/jci26078

Qin, L., Li, G., Qian, X., Liu, Y., Wu, X., Liu, B., et al. (2005). Interactive role of the toll-like receptor 4 and reactive oxygen species in LPS-induced microglia activation. Glia 52, 78-84. doi: 10.1002/glia.20225

Qin, Y., Liu, Y., Hao, W., Decker, Y., Tomic, I., Menger, M. D., et al. (2016). Stimulation of TLR4 attenuates Alzheimer's disease-related symptoms and pathology in tau-transgenic mice. J. Immunol. 197, 3281-3292. doi: $10.4049 /$ jimmunol.1600873

Ransohoff, R. M., and Perry, V. H. (2009). Microglial physiology: unique stimuli, specialized responses. Annu. Rev. Immunol. 27, 119-145. doi: 10.1146/annurev. immunol.021908.132528

Reed-Geaghan, E. G., Savage, J. C., Hise, A. G., and Landreth, G. E. (2009). $\mathrm{CD} 14$ and toll-like receptors 2 and 4 are required for fibrillar $\mathrm{A} \beta$-stimulated microglial activation. J. Neurosci. 29, 11982-11992. doi: 10.1523/JNEUROSCI. 3158-09.2009

Rezazadeh, M., Khorrami, A., Yeghaneh, T., Talebi, M., Kiani, S. J., Heshmati, Y., et al. (2016). Genetic factors affecting late-onset Alzheimer's disease susceptibility. Neuromolecular Med. 18, 37-49. doi: 10.1007/s12017-015 $-8376-4$

Richard, K. L., Filali, M., Prefontaine, P., and Rivest, S. (2008). Toll-like receptor 2 acts as a natural innate immune receptor to clear amyloid 1-42 and delay the cognitive decline in a mouse model of Alzheimer's disease. J. Neurosci. 28, 5784-5793. doi: 10.1523/JNEUROSCI.114608.2008

Rock, F. L., Hardiman, G., Timans, J. C., Kastelein, R. A., and Bazan, J. F. (1998). A family of human receptors structurally related to Drosophila Toll. Proc. Natl. Acad. Sci. U S A 95, 588-593. doi: 10.1073/pnas.95.2.588

Ros-Bernal, F., Hunot, S., Herrero, M. T., Parnadeau, S., Corvol, J.-C., Lu, L., et al. (2011). Microglial glucocorticoid receptors play a pivotal role in regulating dopaminergic neurodegeneration in parkinsonism. Proc. Natl. Acad. Sci. U S A 108, 6632-6637. doi: 10.1073/pnas.1017820108

Rosenberger, K., Derkow, K., Dembny, P., Krüger, C., Schott, E., and Lehnardt, S. (2014). The impact of single and pairwise Toll-like receptor activation on neuroinflammation and neurodegeneration. J. Neuroinflammation 11:166. doi: 10.1186/s12974-014-0166-7

Ruckdeschel, K., Pfaffinger, G., Haase, R., Sing, A., Weighardt, H., Häcker, G., et al. (2004). Signaling of apoptosis through TLRs critically involves toll/IL-1 receptor domain-containing adapter inducing IFN- $\beta$, but not MyD88, in bacteria-infected murine macrophages. J. Immunol. 173, 3320-3328. doi: $10.4049 /$ jimmunol.173.5.3320

Sarlus, H., and Heneka, M. T. (2017). Microglia in Alzheimer's disease. J. Clin. Invest. 127, 3240-3249. doi: 10.1172/JCI90606

Savino, F., Galliano, I., Garro, M., Savino, A., Manzoni, P., Daprà, V., et al. (2018). Changes in the messenger RNA expression of toll-like receptors 2 and 4 in healthy infants according to age. Am. J. Perinatol. $35,583-588$. doi: 10.1055/s0038-1639363

Schafer, S. L., Lin, R., Moore, P. A., Hiscott, J., and Pitha, P. M. (1998). Regulation of type I interferon gene expression by interferon regulatory factor-3. J. Biol. Chem. 273, 2714-2720. doi: 10.1074/jbc.273.5.2714

Scholtzova, H., Kascsak, R. J., Bates, K. A., Boutajangout, A., Kerr, D. J., Meeker, H. C., et al. (2009). Induction of toll-like receptor 9 signaling as a method for ameliorating Alzheimer's disease-related pathology. J. Neurosci. 29, 1846-1854. doi: 10.1523/JNEUROSCI.5715-08.2009

Shao, Q.-H., Yan, W.-F., Zhang, Z., Ma, K.-L., Peng, S.-Y., Cao, Y.-L., et al. (2018). Nurr1: a vital participant in the TLR4-NF- $\mathrm{B}$ signal pathway stimulated by $\alpha$-synuclein in BV-2 cells. Neuropharmacology doi: 10.1016/j.neuropharm. 2018.04.008 [Epub ahead of print].
Smith, S. M. C., Friedle, S. A., and Watters, J. J. (2013). Chronic intermittent hypoxia exerts CNS region-specific effects on rat microglial inflammatory and TLR4 gene expression. PLoS One 8:e81584. doi: 10.1371/journal.pone. 0081584

Song, M., Jin, J., Lim, J.-E., Kou, J., Pattanayak, A., Rehman, J. A., et al. (2011). TLR4 mutation reduces microglial activation, increases $A \beta$ deposits and exacerbates cognitive deficits in a mouse model of Alzheimer's disease. J. Neuroinflammation 8:92. doi: 10.1186/1742-2094-8-92

Sprenkle, N. T., Sims, S. G., Sánchez, C. L., and Meares, G. P. (2017). Endoplasmic reticulum stress and inflammation in the central nervous system. Mol. Neurodegener. 12:42. doi: 10.1186/s13024-017-0183-y

Stefanova, N., Fellner, L., Reindl, M., Masliah, E., Poewe, W., and Wenning, G. K. (2011). Toll-like receptor 4 promotes $\alpha$-synuclein clearance and survival of nigral dopaminergic neurons. Am. J. Pathol. 179, 954-963. doi: 10.1016/j. ajpath.2011.04.013

Tahara, K., Kim, H.-D., Jin, J.-J., Maxwell, J. A., Li, L., and Fukuchi, K.-I. (2006). Role of toll-like receptor signalling in a uptake and clearance. Brain 129, 3006-3019. doi: 10.1093/brain/awl249

Takeda, K., and Akira, S. (2004). TLR signaling pathways. Semin. Immunol. 16, 3-9. doi: 10.1016/j.smim.2003.10.003

Takeda, K., Kaisho, T., and Akira, S. (2003). Toll-like receptors. Annu. Rev. Immunol. 21, 335-376. doi: 10.1146/annurev.immunol.21.120601.141126

Takeuchi, O., Kawai, T., Sanjo, H., Copeland, N. G., Gilbert, D. J., Jenkins, N. A., et al. (1999). TLR6: a novel member of an expanding Toll-like receptor family. Gene 231, 59-65. doi: 10.1016/s0378-1119(99)00098-0

Takeuchi, O., Sato, S., Horiuchi, T., Hoshino, K., Takeda, K., Dong, Z., et al. (2002). Cutting edge: role of toll-like receptor 1 in mediating immune response to microbial lipoproteins. J. Immunol. 169, 10-14. doi: 10.4049/jimmunol. 169.1.10

Tang, S.-C., Arumugam, T. V., Xu, X., Cheng, A., Mughal, M. R., Jo, D. G., et al. (2007). Pivotal role for neuronal Toll-like receptors in ischemic brain injury and functional deficits. Proc. Natl. Acad. Sci. U S A 104, 13798-13803. doi: 10.1073/pnas.0702553104

Tauber, S. C., Ebert, S., Weishaupt, J. H., Reich, A., Nau, R., and Gerber, J. (2009). Stimulation of toll-like receptor 9 by chronic intraventricular unmethylated cytosine-guanine DNA infusion causes neuroinflammation and impaired spatial memory. J. Neuropathol. Exp. Neurol. 68, 1116-1124. doi: 10.1097/nen. 0b013e3181b7fde5

van Noort, J. M., and Bsibsi, M. (2009). Toll-like receptors in the CNS: implications for neurodegeneration and repair. Prog. Brain Res. 175, 139-148. doi: 10.1016/S0079-6123(09)17509-X

Venezia, S., Refolo, V., Polissidis, A., Stefanis, L., Wenning, G. K., and Stefanova, N. (2017). Toll-like receptor 4 stimulation with monophosphoryl lipid A ameliorates motor deficits and nigral neurodegeneration triggered by extraneuronal $\alpha$-synucleinopathy. Mol. Neurodegener. 12:52. doi: 10.1186/s13024-017-0195-7

Viana, S. D., Pita, I. R., Lemos, C., Rial, D., Couceiro, P., Rodrigues-Santos, P., et al. (2017). The effects of physical exercise on nonmotor symptoms and on neuroimmune RAGE network in experimental parkinsonism. J. Appl. Physiol. 123, 161-171. doi: 10.1152/japplphysiol.01120.2016

Vollmar, P., Kullmann, J. S., Thilo, B., Claussen, M. C., Rothhammer, V., Jacobi, H., et al. (2010). Active immunization with amyloid- 1-42 impairs memory performance through TLR2/4-dependent activation of the innate immune system. J. Immunol. 185, 6338-6347. doi: 10.4049/jimmunol.1001765

Walker, D. G., Tang, T. M., and Lue, L. F. (2018). Increased expression of toll-like receptor 3, an anti-viral signaling molecule and related genes in Alzheimer's disease brains. Exp. Neurol. 309, 91-106. doi: 10.1016/j.expneurol.2018.07.016

Walter, S., Doering, A., Letiembre, M., Liu, Y., Hao, W., Diem, R., et al. (2006). The LPS receptor, CD14, in experimental autoimmune encephalomyelitis and multiple sclerosis. Cell. Physiol. Biochem. 17, 167-172. doi: 10.1159/000092078

Walter, S., Letiembre, M., Liu, Y., Heine, H., Penke, B., Hao, W., et al. (2007). Role of the toll-like receptor 4 in neuroinflammation in Alzheimer's disease. Cell. Physiol. Biochem. 20, 947-956. doi: 10.1159/000110455

Wang, F.-X., Liu, S.-Y., Zheng, X., Chen, X., Lu, L.-X., Chen, B., et al. (2015). TLR1 expression in mouse brain was increased in a KA-induced seizure model. Inflamm. Res. 64, 487-495. doi: 10.1007/s00011-015-0828-7

Wang, L.-Z., Tian, Y., Yu, J.-T., Chen, W., Wu, Z.-C., Zhang, Q., et al. (2011). Association between late-onset Alzheimer's disease and microsatellite 
polymorphisms in intron II of the human toll-like receptor 2 gene. Neurosci. Lett. 489, 164-167. doi: 10.1016/j.neulet.2010.12.008

Wang, Y.-W., Zhou, Q., Zhang, X., Qian, Q.-Q., Xu, J.-W., Ni, P.-F., et al. (2017). Mild endoplasmic reticulum stress ameliorates lipopolysaccharideinduced neuroinflammation and cognitive impairment via regulation of microglial polarization. J. Neuroinflammation 14:233. doi: 10.1186/s12974-017$1002-7$

Weintraub, M. K., Kranjac, D., Eimerbrink, M. J., Pearson, S. J., Vinson, B. T., Patel, J., et al. (2014). Peripheral administration of poly I:C leads to increased hippocampal amyloid- $\beta$ and cognitive deficits in a non-transgenic mouse. Behav. Brain Res. 266, 183-187. doi: 10.1016/j.bbr.2014. 03.009

Wendeln, A. C., Degenhardt, K., Kaurani, L., Gertig, M., Ulas, T., Jain, G., et al. (2018). Innate immune memory in the brain shapes neurological disease hallmarks. Nature 556, 332-338. doi: 10.1038/s41586-018-0023-4

Woulfe, J. M., Gray, M. T., Gray, D. A., Munoz, D. G., and Middeldorp, J. M. (2014). Hypothesis: a role for EBV-induced molecular mimicry in Parkinson's disease. Parkinsonism Relat. Disord. 20, 685-694. doi: 10.1016/j.parkreldis. 2014.02.031

Wu, W. Y.-Y., Kang, K.-H., Chen, S. L.-S., Chiu, S. Y.-H., Yen, A. M.-F., Fann, J. C.-Y., et al. (2015). Hepatitis C virus infection: a risk factor for Parkinson's disease. J. Viral Hepat. 22, 784-791. doi: 10.1111/jvh.12392

Yamamoto, M., Sato, S., Hemmi, H., Hoshino, K., Kaisho, T., Sanjo, H., et al. (2003a). Role of adaptor TRIF in the MyD88-independent toll-like receptor signaling pathway. Science 301, 640-643. doi: 10.1126/science.1087262

Yamamoto, M., Sato, S., Hemmi, H., Uematsu, S., Hoshino, K., Kaisho, T., et al. (2003b). TRAM is specifically involved in the Toll-like receptor 4-mediated MyD88-independent signaling pathway. Nat. Immunol. 4, 1144-1150. doi: $10.1038 /$ ni986

Yao, L., Kan, E. M., Lu, J., Hao, A., Dheen, S. T., Kaur, C., et al. (2013). Toll-like receptor 4 mediates microglial activation and production of inflammatory mediators in neonatal rat brain following hypoxia: role of TLR4 in hypoxic microglia. J. Neuroinflammation 10:23. doi: 10.1186/1742-20 94-10-23

Yousif, N. M., de Oliveira, A. C. P., Brioschi, S., Huell, M., Biber, K., and Fiebich, B. L. (2018). Activation of $\mathrm{EP}_{2}$ receptor suppresses Poly(I: C) and LPS-mediated inflammation in primary microglia and organotypic hippocampal slice cultures: contributing role for MAPKs. Glia 66, 708-724. doi: 10.1002/glia.23276
Yu, J.-T., Mou, S.-M., Wang, L.-Z., Mao, C.-X., and Tan, L. (2011a). Tolllike receptor $2-196$ to -174 del polymorphism influences the susceptibility of Han Chinese people to Alzheimer's disease. J. Neuroinflammation 8:136. doi: $10.1186 / 1742-2094-8-136$

Yu, J.-T., Sun, Y.-P., Ou, J.-R., Cui, W.-Z., Zhang, W., and Tan, L. (2011b). No association of toll-like receptor 2 polymorphisms with Alzheimer's disease in Han Chinese. Neurobiol. Aging 32, 1924.e1-1924.e3. doi: 10.1016/j. neurobiolaging.2011.03.023

Zhang, Y.-K., Liu, J.-T., Peng, Z.-W., Fan, H., Yao, A.-H., Cheng, P., et al. (2013). Different TLR4 expression and microglia/macrophage activation induced by hemorrhage in the rat spinal cord after compressive injury. J. Neuroinflammation 10:112. doi: 10.1186/1742-2094-10-112

Zhang, F. X., Kirschning, C. J., Mancinelli, R., Xu, X.-P., Jin, Y., Faure, E., et al. (1999). Bacterial lipopolysaccharide activates nuclear factor- $\mathrm{KB}$ through interleukin-1 signaling mediators in cultured human dermal endothelial cells and mononuclear phagocytes. J. Biol. Chem. 274, 7611-7614. doi: 10.1074/jbc. 274.12.7611

Zhang, Q., Wu, H. H., Wang, Y., Gu, G. J., Zhang, W., and Xia, R. (2016). Neural stem cell transplantation decreases neuroinflammation in a transgenic mouse model of Alzheimer's disease. J. Neurochem. 136, 815-825. doi: 10.1111/jnc. 13413

Zhao, W., Beers, D. R., Henkel, J. S., Zhang, W., Urushitani, M., Julien, J.-P., et al. (2010). Extracellular mutant SOD1 induces microglial-mediated motoneuron injury. Glia 58, 231-243. doi: 10.1002/glia.20919

Zhou, P., Weng, R., Chen, Z., Wang, R., Zou, J., Liu, X., et al. (2016). TLR4 signaling in $\mathrm{MPP}^{+}$-induced activation of BV-2 cells. Neural Plast. 2016:5076740. doi: $10.1155 / 2016 / 5076740$

Conflict of Interest Statement: The authors declare that the research was conducted in the absence of any commercial or financial relationships that could be construed as a potential conflict of interest.

Copyright (C) 2018 Fiebich, Batista, Saliba, Yousif and de Oliveira. This is an open-access article distributed under the terms of the Creative Commons Attribution License (CC BY). The use, distribution or reproduction in other forums is permitted, provided the original author(s) and the copyright owner(s) are credited and that the original publication in this journal is cited, in accordance with accepted academic practice. No use, distribution or reproduction is permitted which does not comply with these terms. 